\title{
Mutation profiling in eight cases of vagal paragangliomas
}

Anna V. Kudryavtseva ${ }^{*}$, Dmitry V. Kalinin², Vladislav S. Pavlov', Maria V. Savvateeva', Maria S. Fedorova', Elena A. Pudova', Anastasiya A. Kobelyatskaya', Alexander L. Golovyuk², Zulfiya G. Guvatova', George S. Razmakhaev ${ }^{3}$, Tatiana B. Demidova ${ }^{4}$, Sergey A. Simanovsky ${ }^{4}$, Elena N. Slavnova ${ }^{3}$, Andrey A. Poloznikov ${ }^{3}$, Andrey P. Polyakov ${ }^{3}$, Nataliya V. Melnikova', Alexey A. Dmitriev' ${ }^{1}$, George S. Krasnov ${ }^{1}$ and Anastasiya V. Snezhkina ${ }^{1}$ (D)

From 11th International Young Scientists School "Systems Biology and Bioinformatics" - SBB-2019

Novosibirsk, Russia. 24-28 June 2019

\begin{abstract}
Background: Vagal paragangliomas (VPGLs) belong to a group of rare head and neck neuroendocrine tumors. VPGLs arise from the vagus nerve and are less common than carotid paragangliomas. Both diagnostics and therapy of the tumors raise significant challenges. Besides, the genetic and molecular mechanisms behind VPGL pathogenesis are poorly understood.

Methods: The collection of VPGLs obtained from 8 patients of Russian population was used in the study. Exome library preparation and high-throughput sequencing of VPGLs were performed using an Illumina technology.

Results: Based on exome analysis, we identified pathogenic/likely pathogenic variants of the SDHx genes, frequently mutated in paragangliomas/pheochromocytomas. SDHB variants were found in three patients, whereas SDHD was mutated in two cases. Moreover, likely pathogenic missense variants were also detected in SDHAF3 and SDHAF4 genes encoding for assembly factors for the succinate dehydrogenase (SDH) complex. In a patient, we found a novel variant of the IDH2 gene that was predicted as pathogenic by a series of algorithms used (such as SIFT, PolyPhen2, FATHMM, MutationTaster, and LRT). Additionally, pathogenic/likely pathogenic variants were determined for several genes, including novel genes and some genes previously reported as associated with different types of tumors.

Conclusions: Results indicate a high heterogeneity among VPGLs, however, it seems that driver events in most cases are associated with mutations in the SDHx genes and SDH assembly factor-coding genes that lead to disruptions in the SDH complex.
\end{abstract}

Keywords: Vagal paraganglioma, Pathogenic/likely pathogenic mutations, SDHx genes, SHD assembly factor-coding genes, Exome, High-throughput sequencing

\footnotetext{
* Correspondence: rhizamoeba@mail.ru

${ }^{1}$ Engelhardt Institute of Molecular Biology, Russian Academy of Sciences, Moscow, Russia

Full list of author information is available at the end of the article
}

C The Author(s). 2020 Open Access This article is licensed under a Creative Commons Attribution 4.0 International License, which permits use, sharing, adaptation, distribution and reproduction in any medium or format, as long as you give appropriate credit to the original author(s) and the source, provide a link to the Creative Commons licence, and indicate if changes were made. The images or other third party material in this article are included in the article's Creative Commons licence, unless indicated otherwise in a credit line to the material. If material is not included in the article's Creative Commons licence and your intended use is not permitted by statutory regulation or exceeds the permitted use, you will need to obtain permission directly from the copyright holder. To view a copy of this licence, visit http://creativecommons.org/licenses/by/4.0/ The Creative Commons Public Domain Dedication waiver (http://creativecommons.org/publicdomain/zero/1.0/) applies to the data made available in this article, unless otherwise stated in a credit line to the data. 


\section{Background}

Vagal paraganglioma (VPGL) is a neuroendocrine tumor that arises from paraganglia along the course of the vagus nerve (cranial nerve $\mathrm{X}$ ), the dominant nerve of the parasympathetic division of the autonomic nervous system [1]. The role of vagus paraganglia is not clear enough; they have been proposed to serve a chemoreceptive function and to participate in the immune response to infections [2, 3]. VPGL presents as a painless and slow-growing mass involving the parapharyngeal space [4]. The symptoms of VPGL depend on tumor location. They range from pulsatile tinnitus/ringing in the ear to deficits of cranial nerves (such as hoarseness and dysphagia) and intracranial extension associated with an increased risk of death [5]. VPGL accounts for approximately $13 \%$ of all head and neck paragangliomas (HNPG Ls) and occurs more frequently in women $[6,7]$. Surgical resection is a primary treatment for VPGL, whereas radiation therapy is used in case of malignant and unresectable tumors [8, 9]. VPGL has a lower risk for metastasis compared with carotid paraganglioma (CPGL) [10].

About 30\% of HNPGLs develop as inherited tumors [11, 12]. A familial form of HNPGLs predominantly occurs as paraganglioma syndromes and results from mutations in $S D H A, S D H B, S D H C, S D H D$, and $S D H A F 2$ genes, encoding for succinate dehydrogenase (SDH; mitochondrial complex II) components [11]. Mutations in the SDHD gene are the most frequently found in HNPGLs, followed by $S D H B$ and $S D H C$ mutations $[13,14]$. The inheritance pattern for $S D H A, S D H B$ and $S D H C$ is autosomal dominant, whereas for $S D H D$ and $S D H A F 2$ the transmission pattern is consistent with genomic imprinting (with a predominance of paternal transmission) [15]. SDHAF2 variants rarely present in paragangliomas/pheochromocytomas (PGLs/ PCCs) $[16,17]$. Familial mutations in $S D H A$ have been reported for Leigh syndrome [18] and, most recently, a few have been identified for HNPGLs [19-21]. Mutations in the VHL, TMEM127, RET, NF1, and MAX genes also harbor the risk for HNPGL development [22, 23]. Additionally, potentially driver somatic/germline variants were identified in several other genes, such as $A R N T, B A P 1, B R A F, B R C A 1$, BRCA2, CDKN2A, CSDE1, FGFR3, IDH1, KIF1B, KMT2D, MEN1, RET, JAG1, PRDM2, PRDM8, SETD2, ASPM, ZIC, and GRIK1 [21, 24, 25].

In this work, we performed whole-exome sequencing of VPGLs from 8 patients. Pathogenic/likely pathogenic mutations were identified and discussed for each individual case and in relation to overall VPGL pathogenesis.

\section{Methods}

Tumor samples

Formalin-fixed paraffin-embedded (FFPE) VPGL tissues were collected at the Vishnevsky Institute of Surgery, Ministry of Health of the Russian Federation. VPGLs were obtained from 8 patients who did not receive any radiotherapy or chemotherapy before surgery. All patients provided a written informed consent for their participation in the study. This study was approved by the ethics committee from the Vishnevsky Institute of Surgery and performed according to the Declaration of Helsinki (1964).

DNA isolation, exome library preparation and sequencing Sections from FFPE tissues were prepared on glass slides and stained with hematoxylin-eosin (H\&E). Tumor areas consisting of no less than $80 \%$ of tumor cells were chosen in unstained sections according to reference H\&E-stained slides and transferred into microcentrifuge tubes. DNA was isolated from 9 different tumor tissues using the High Pure FFPET DNA Isolation Kit (Roche, Switzerland). Among the 9 tumors, 2 belonged to 1 patient (Patient 2) and samples were obtained from different FFPE blocks. DNA concentration was measured on a Qubit 2.0 fluorometer (Thermo Fisher Scientific, USA). DNA quality was tested using an Agilent 2100 Bioanalyzer (Agilent Technologies, USA) and quantitative PCR (qPCR) was performed with a QuantumDNA Kit (Evrogen, Russia).

In total, 9 exome libraries were prepared using the Nextera Rapid Capture Exome Kit (Illumina, USA) according to the manufacturer's instructions. High-output sequencing was performed on a NextSeq 500 System (Illumina) with paired-end $76 \times 2$ cycles. At least $300 \times$ coverage for each sample was obtained. Raw sequence data were deposited into the NCBI Sequence Read Archive (SRA) under accession number PRJNA561073.

\section{Bioinformatics analysis}

Illumina paired-end reads were subjected to quality control with FastQC. Then, reads were trimmed and adapters removed using Trimmomatic [26]. Next, reads were mapped to the reference human genome GRCh37.75/hg19 (Ensembl) using BWA [27]. Derived BAM files were sorted with SAMtools [28] and processed with Picard tools (files were reordered and assigned to group names, whereas duplicated reads were marked; https://broadinstitute.github.io/picard/index. html). Besides, we performed base quality score recalibration using GATK4 (v. 4.1.2) and dbSNP (build 144) [29]. Variant calling was performed with GATK 4.1.2 HaplotypeCaller [29]. We turned on StrandBiasBySample, StrandOddsRatio, and BaseQualityRankSumTest annotations in order to exclude false positives. Additionally, we excluded SNVs in polyN motifs, such as GGGTG > GGGGG and CCCCG > CCCCC, which are frequently missequenced by Illumina NextSeq 500 system. 
The derived list of variants was annotated using Annovar [30]. For this part of the analysis, we included allele population frequencies databases (gnomAD, $1000 \mathrm{Ge}$ nomes Project, Kaviar, ESP6500, and ExAC), dbSNP, ClinVar, and COSMIC annotations, localization in a protein domain (Interpro), and site conservation data (phastCons and PhyloP). Additionally, we included annotations by DANN, CADD, SIFT, PolyPhen-2, FATH MM, MutationAssessor, MutationTaster, LRT, PROVEAN, M-CAP, Meta-SVM, and MetaLR in order to assess the pathogenicity of the variants. Finally, the "pathogenicity score" was calculated based on the population frequency, site conservation, and the summary weighted score across several prediction algorithms. Additionally, obtained "pathogenicity scores" for variants annotated as pathogenic by the ClinVar or contained in the COSMIC v70 database were increased.

\section{Results and discussion}

We performed whole-exome sequencing of VPGLs from 8 patients. Normal tissues from the same patients were not available due to the fact that samples were originally collected as archive material. In VPGLs, we identified pathogenic/likely pathogenic variants of genes that were previously shown to be associated with PGLs/PCCs: VHL, SDHx, NF1, RET, HRAS, KRAS, EPAS1 (HIF2A), ATRX, CSDE1, BRAF, FGFR1, FGFR2, FGFR3, FGFR4, FGFRL1, SETD2, ARNT, TP53, TP53BP1, TP53BP2, TP53I13, KMT2D, BAP1, IDH1, IDH2, SDHAF1, SDHA P2, FH, EGLN1, MDH2, TMEM127, MAX, KIF1B, $M E N 1, G D N F, G N A S, C D K N 2 A, B R C A 1$, and BRCA2 [21] as well as in other groups of genes (Additional file 1). Pathogenicity of the variants was predicted based on several resources, including prediction tools, population frequency databases, open sources on the clinical significance of variants, and algorithms for estimation of sequence conservation scores. The description of each case in detail is presented below. Besides, Table 1 shows the main clinic pathological characteristics of the patients. All patients were female.

\section{Patient 1}

A 70-year-old female presented with a volumetric formation on the left submandibular region with a concomitant diagnosis of arterial hypertension. Ultrasound study and computed tomography (CT) revealed a tumor $28 \times 21 \times 21 \mathrm{~mm}$ in size at the left carotid bifurcation. At surgery, the tumor originating from the vagus nerve was excised. Histological examination of postoperative material confirmed a paraganglioma of solid trabecular structure.

Exome analysis of the tumor revealed no variants in the potentially causative genes for PGLs/PCCs. However, we found likely pathogenic variants characterized by high "pathogenicity scores" as well as by frameshift mutations in several tumor-associated genes, such as CYSL TR2, GPX2, ENPP7, CD34, UBA7, and others (Additional file 1).

For the UTS2R gene, we identified a likely pathogenic variant, NM_018949: c.C313A, p.P105T (chr17: 80332513, rs140576840), that had not been reported in the ClinVar or COSMIC databases before. UTS2R encodes for urotensin II receptor (G-protein coupled receptor 14, GPR14), a protein that has been shown to be involved in PCC pathogenesis. It has been shown that the incubation of human pheochromocytoma cells (primary culture) with urotensin II promotes cell proliferation [31]. Moreover, UTS2R mRNA levels are decreased in PCC [32].

A likely pathogenic variant, NM_004804: c.C296T, p.T99I (chr2: 96933370, rs780418079), was also determined for the CIAO1 gene. This variant had not been described neither in the ClinVar nor in the COSMIC databases. The CIAO1 gene encodes for the cytosolic ironsulfur assembly component 1 participating in energy metabolism. Alterations in CIAO1 are associated with

Table 1 Clinic pathologic characteristics of the patients with VPGLS

\begin{tabular}{|c|c|c|c|}
\hline Patient & Age, yr & Tumor localization (left/right side of the neck) & SDHX and SDHAF1-4 mutations \\
\hline 1 & 70 & Left & No \\
\hline 2 & 52 & Right & $S D H B$ \\
\hline 3 & 41 & Left & $\begin{array}{l}\text { SDHAF3 } \\
\text { SDHAF4 }\end{array}$ \\
\hline 4 & 51 & Left & No \\
\hline 5 & 50 & Right & $\begin{array}{l}\text { SDHB } \\
\text { SDHAF4 }\end{array}$ \\
\hline $6^{\mathrm{a}}$ & 50 & Right & $S D H D$ \\
\hline 7 & 26 & Left & $S D H B$ \\
\hline 8 & 68 & Left & $S D H D$ \\
\hline
\end{tabular}

a Patient with multiple paragangliomas 
hereditary PGL/PCC syndromes according to the MalaCards database (https://www.malacards.org/).

The likely pathogenic missense variant NM_017558: c.G1352C, p.R451P (chr16: 71127814, rs7200485) of the HYDIN gene was also identified in this VPGL. Nevertheless, the variant had not been described in the ClinVar or COSMIC databases. Noteworthy, we have previously shown that HYDIN is characterized by a high mutation rate in CPGL and could be involved in its pathogenesis [33].

Additionally, we found several likely pathogenic variants reported in the COSMIC database for the following genes: CD109 (COSM1621920; liver and lung cancer), CYSLTR2 (COSM1367341; colon cancer), DENND6B (COSM1035425; endometrial cancer), and OR9I1 (COSM385271; lung cancer).

\section{Patient 2}

A 52-year-old female, complaining from arterial hypertension, was diagnosed with a right-sided neck mass. After a year, an excisional biopsy was performed and, a year later, several complications appeared: a deviation of the right side of the tongue, hoarseness, troublesome swallowing, and right papilla atrophy. A year after the appearance of these complications, the patient was hospitalized for surgery. It was then when the presence of a VPGL on the right side of the neck, in the area of the carotid artery bifurcation, was determined by color duplex scanning. It was also found that regional lymph nodes were increased in size. A right-sided hypervascularized VPGL, $72 \times 27 \times 27 \mathrm{~mm}$ in size, spreading from the jugular hole to the carotid bifurcation, involving both the carotid artery and the hyoid nerve, was revealed by $\mathrm{CT}$ scans with $3 \mathrm{D}$ reconstruction, confirming the diagnosis. An ultrasound study of internal organs showed a moderately pronounced bilateral nephropathy and diffuse changes in pancreatic tissue. At surgery, it was found that the tumor originated from the vagus nerve and reached the base of the skull involving the hyoid nerve. The tumor was removed along with resection of both the vagus and hyoid nerves, the outer carotid artery, and regional lymph nodes. Histological examination revealed a typical organoid paraganglioma of alveolar and trabecular structure without regional lymph node metastasis. The patient was extubated in the operating room; however, the early postoperative period was complicated by cardiopulmonary failure, followed by aspiration pneumonia. The patient died 9 days after surgery.

For this patient, we performed whole-exome sequencing of two tumor samples from different FFPE blocks to validate sequencing data. Results obtained from both samples were in concordance with each other (Additional file 1). We detected a likely pathogenic missense variant in the $S D H B$ gene, NM_003000: c.A307G, p.M103V (chr1: 17355211, rs140178341). This variant is described in the ClinVar database as a variant with uncertain clinical significance. Its presence was previously detected for Cowden syndrome 2 (a hereditary cancerpredisposing syndrome), gastrointestinal stromal tumor, PGLs/PCCs, and PGL 4 syndrome, during clinical testing. Additionally, two novel frameshift mutations were found in SDHB, NM_003000: c.308_309insTAAG, p.M103fs (chr1: 17355209) and NM_003000: c.304 305insATGAT, p.A102fs (chr1: 17355213). A likely pathogenic missense variant was also observed in $A R N T$, NM_001197325: c.C1834T, p.R612C (chr1: 150788806, rs778430234); a variant that had not been previously reported, neither in the ClinVar nor in the COSMIC databases. However, likely pathogenic variants in the ARNT gene were earlier determined in CPGLs [21].

According to several prediction algorithms, likely pathogenic variants as well as frameshift and stop-gain mutations were also identified in other genes (Additional file 1). One of these distinctive genes is a novel likely pathogenic variant for RXFP1, NM_021634: c.G172A, p.D58N (chr4: 159493972). This gene encodes for the relaxin family peptide receptor 1 , a protein related to RLN2/RXFP1 signaling that has been shown to mediate tumor cell motility and invasion in breast, thyroid, prostate, and endometrial cancers [34-38]. The induction of the CTRP8-RXFP1 ligand-receptor system increases the migration of glioblastoma cells [39]. Moreover, RXFP1 participates in cancer chemoresistance [40].

A likely pathogenic variant NM_024776: c.C2908T, p.R970C (crh15: 77471361, rs117879553) in the PEAK1 gene was also revealed in this patient's VPGL. The variant had not been described in the ClinVar or COSMIC databases. However, numerous studies have reported the involvement of PEAK1 in tumorigenesis [41-45].

The SLIT2 gene encodes for the slit homolog 2 protein, a ligand of the ROBO immunoglobulin receptor family. The SLIT/ROBO pathway plays an important role in axon guidance and neuronal precursor cell migration as well as in the regulation of angiogenesis [46]. We determined a likely pathogenic variant NM_004787: c.A934G, p.I312V (chr4: 20512137, rs139850475) for this gene. According to data from the literature, the SLIT/ ROBO pathway has a dual effect in tumor growth and progression. On the one hand, SLIT/ROBO promotes tumor cell proliferation and migration [47]. On the other hand, it has been reported that SLIT2 is frequently inactivated in gliomas by hypermethylation at the $\mathrm{CpG}$ island within its promoter region and can act as a tumor suppressor gene [48].

A likely pathogenic variant was also found in the AMPH gene, NM_001635: c.A2024G, p.Q675R (chr7: 38424483, rs147019216T). AMPH encodes for 
amphiphysin 1, localized in nerve terminals of mature neurons and participates in clathrin-mediated endocytosis $[49,50]$. Noteworthy, the expression of amphiphysin 1 was detected in patients with stiff-person syndrome associated with breast and lung cancer, and melanoma [51]. Additionally, $A M P H$ knockdown reduces apoptosis and promotes cell cycle progression and migration of breast cancer cells [52].

In the HAPLN3 gene, we also identified a likely pathogenic variant, NM_178232: c.G316A, p.G106R (chr15: 89424765, rs140982817), described in the COSMIC database as associated with lung and caecum cancer (COSM1375297).

\section{Patient 3}

A 41-year-old female was examined for the presence of neoplasm on the left side of the neck. It was noticed that the neoplasm was detected 10 years before the examination and grew fast for the last five years only. CT analysis showed that the tumor was located at the bifurcation of the common carotid artery (CCA) (on the posterior surface of the formation) from the thyroid upper pole level. The presence of a homogeneous structure; a soft tissue density mass with smooth, sufficiently clear hilly contours, measuring $70 \times 47 \times 42 \mathrm{~mm}$, was determined. The tumor belonged to the anterior medial surface of the outer carotid artery (OCA) (pushing the vessel laterally) and was located between the external and internal carotid arteries. The jugular vein was also involved by the mass. The upper pole of the formation was $40 \mathrm{~mm}$ lower than the base of the skull. The tumor was removed after embolization to reduce blood loss. Histological testing of the operation material showed a mature paraganglioma with an alveolar and trabecular structure without any symptom of lymph node metastasis.

Exome analysis of the VPGL revealed the existence of likely pathogenic missense variants of both the $S D H A F 3$ and SDHAF4 genes: NM_020186: c.T157C, p.F53L (chr7: 96747192, rs62624461) and NM_145267: c.C223T, p.P75S (chr6: 71298323, rs146446063), respectively (Additional file 1). These variants had not been reported in the ClinVar or COSMIC databases before. Both genes encode for SDH assembly factors and play a critical role in SDH stability and activity. Previously, we found a likely pathogenic missense variant of SDHAF3 from CPGL (not published). A variant of this gene, which may probably damage the protein function (according to the in silico tools used for analysis), was determined in familial and sporadic PGLs/PCCs [53].

For VPGL, we revealed several likely pathogenic variants of the COL19A1 (COSM1235991; related to plasma cell myeloma and lung cancer), SEC31B (COSM913945; involved in endometrial and colorectal cancer), THSD7B
(COSM247830; associated with prostate cancer), and TIAM1 (COSM1566097, COSM1566096; related to rectum cancer) genes, which have been previously described in the COSMIC database.

Additionally, we identified likely pathogenic variants of CRNN, CYP4B1, ELL, ENPP7, FAT2, NCOR2, SART1, TIAM1, VIM, and other genes involved in tumorigenesis according to literature data.

\section{Patient 4}

A 51-year-old female patient was examined for complaints of swelling on the left side of the neck, hoarseness, morning headaches, weakness, and poor sleep. Enlarged lymph nodes were bothering her since a sore throat presented two years before. Duplex scanning (DS) and CT revealed a solid tumor $26 \times 19 \times 29 \mathrm{~mm}$ in size on the left side of the neck at the submandibular region, lateral to the internal carotid artery (ICA) and the OCA; the tumor bordered the arteries. During surgery, it was found that both the CCA bifurcation and initial parts of the ICA and OCA were involved in the tumor. A thickening of the trunk of the vagus nerve was also detected; it was found that the tumor originated precisely from the nerve. Besides, the upper pole of the tumor was reaching the base of the skull and the proximal part of the hypoglossal nerve was intimately soldered to the tumor capsule for as long as $5 \mathrm{~mm}$. The glossopharyngeal nerve, adjacent to the upper pole of the tumor, was also intimately associated to the capsule of the tumor for as long as 5 to $7 \mathrm{~mm}$. The tumor was resected along with the proximal end of the vagus nerve. Histological examination revealed a mature paraganglioma with alveolar and trabecular structure.

In the VPGL of this patient, we found no pathogenic/ likely pathogenic variants for any of the PGL/PCC potentially causative genes, including $S D H x$ (Additional file 1). Nevertheless, for several genes, we identified likely pathogenic variants reported in the COSMIC database and associated with different types of cancer: $A C A D 11$ (COSM3695823; colon cancer), MTNR1B (COSM1561913; rectum, lung, liver, and colorectal cancer), NTF4 (COSM3404440; glioma and rhabdomyosarcoma), PATZ1 (COSM273076; acute lymphoblastic leukaemia and colon cancer), SAMD9L (COSM3784101; prostate cancer), and TRIM16 (COSM401683; lung cancer).

A likely pathogenic variant was also revealed for the $A M B R A 1$ gene, involved in cancer development and chemotherapy resistance [54]. Several other genes with likely pathogenic variants that were previously shown to participate in tumorigenesis were also found within this patient's exome. For example, the CHST4 gene, which is associated with colon mucinous adenocarcinoma (MalaCards database); CLCA4, a tumor suppressor gene 
encoding for the calcium-activated chloride channel A4 that can inhibit tumor cell proliferation, migration, and invasion [55, 56]; ESR1, characterized by mutations responsible for the resistance to endocrine therapy in breast cancer [57]; P2RY1, involved in the regulation of multidrug chemoresistance of bladder cancer cells [58]; and PATZ1, which acts as a tumor suppressor gene in thyroid cancer and is associated with the development of testicular tumors, sarcoma, and lung cancer [59-62]. Furthermore, we found alterations in the PRKCI gene related to many tumors [63-65] and WIF1 hypermethylation, frequently observed in cancer cells [66-69].

\section{Patient 5}

A 50-year-old female patient troubled by intense dizziness for several days, mainly during spring and autumn, for the last ten years. The patient self-detected a mass in the right submandibular region. After visualization by ultrasound study, a cyst of the neck was suspected and an attempt to remove it was unsuccessful, leading to suspicion of a paraganglioma. DS showed a $56 \times 34 \mathrm{~mm}$ body in the CCA bifurcation, involving the initial parts of both the OCA and ICA. The patient was hospitalized for follow-up and surgical treatment. Further studies by CT imaging revealed a neck mass $45 \times 32 \times 47 \mathrm{~mm}$ in size next to the ICA and the OCA, whereas an angiography showed a VPGL on the right side of the neck. The lower pole of the neoplasm was located $10 \mathrm{~mm}$ higher than the carotid bifurcation, whilst the upper pole was $30 \mathrm{~mm}$ lower than the base of the skull. As an attempt to reduce blood loss, an embolization was performed first, followed by paraganglioma excision with right ICA resection. Histological analysis of the tissues revealed a mature paraganglioma with alveolar and trabecular structure.

Exome analysis of the VPGL revealed likely pathogenic variants in several PGL/PCC potentially causative genes: $S D H B, S D H A F 4, F G F R L 1$, and IDH2 (Additional file 1). A splice acceptor mutation identified in the $S D H B$ gene (chr1: 17350571, rs786201161) was described as a germline pathogenic variant in the ClinVar database. This variant has been previously reported in association with an SDHB-related disorder, hereditary cancerpredisposing syndrome, gastrointestinal stromal tumor, and hereditary PGL/PCC syndromes [70-72]. The mutation destroys the canonical splice acceptor site within intron 5 of the $S D H B$ gene and is expected to cause abnormal gene splicing, likely resulting in an absent or disrupted protein product. For SDHAF4, we found a novel likely pathogenic missense mutation NM_145267: c.C223T, p.P75S (chr6: 71298323, rs146446063). The likely pathogenic missense mutation identified in the FGFRL1 gene, NM_001004356: c.C442T, p.R148C (chr4: 1017613, rs201696860), has not been previously reported in the ClinVar database; however, it was detected in lung adenocarcinoma and described in the COSMIC database (COSM119740). Finally, in the $I D H 2$ gene, we found a novel mutation NM_001289910: c.T998C, p.L333P (chr15: 90628257) that was predicted as a likely pathogenic variant according to all the prediction algorithms used.

For this VPGL, we also determined likely pathogenic variants in a few genes that were reported in the COSMIC database and associated with different types of cancer: ATP2A1 (COSM1184049; colon cancer), ACAD11 (COSM3695823; colon cancer), ERCC4 (COSM967199; endometrial, colorectal, and papillary thyroid cancer), and VPS13B (COSM3698729, COSM3698730; colon cancer and lung bronchioloalveolar adenocarcinoma). Moreover, likely pathogenic variants were identified in genes reported as tumor-associated ones according to the literature; for example, in CD248, LGR5, LRP1B, PBRM1, and PTPA.

\section{Patient 6}

A 50-year-old female, complaining from arterial hypertension was diagnosed with neck masses on both sides of the body. Both CT and ultrasound study revealed the presence of heterogeneous and hypervascular tumors at the carotid bifurcation areas: a solid neoplasia on the left side and a two-nodal tumor on the right side of the neck. The left tumor, $25 \times 23 \times 17 \mathrm{~mm}$ in size, was resected. Then, the patient was discharged with a planned re-hospitalization to remove the other tumor. After a year, the tumor, $35 \times 20 \mathrm{~mm}$ in size, located directly in the carotid artery bifurcation on the right side of the neck, and one more tumor, $60 \times 20 \mathrm{~mm}$ in size, originating in the vagus nerve, were removed. During the surgery, the lymph node from above the carotid artery bifurcation was also resected. All tumors and lymph nodes were subjected to histological examination. Paragangliomas with no lymph node metastases were revealed.

Using whole-exome sequencing, we found a pathogenic germline mutation in the SDHD gene, NM 003002: c.A305G, p.H102R (chr11: 111959726, rs104894302) (Additional file 1). This variant is described in the ClinVar database as a likely pathogenic germline one and has been found in malignant paraganglioma [73]. At the same position in the SDHD gene (codon 102), a sequence change leading to an amino acid substitution of a histidine for either a leucine, a proline, or a tyrosine was also observed in individuals with paragangliomas [74-76]. This indicates that this histidine residue plays a critical role in SDHD protein function.

In VPGL, we also identified likely pathogenic variants reported in the COSMIC database for the following 
genes: $A B C B 4$ (COSM1092579; endometrial and colorectal cancer), $L H X 8$ (COSM1560500; rectum and stomach cancer), DAPK2 (COSM1678527; clear cell renal cell carcinoma), STARD10 (COSM1475880; breast cancer), and ZNF599 (COSM328007; pancreas cancer).

Additionally, likely pathogenic variants were determined in a number of genes that have been shown to be involved in oncogenic processes. For example, the ARPC5 gene encodes for the actin-related protein $2 / 3$ complex subunit 5 that can affect tumor cell growth, migration, and invasion [77, 78]. MAP 2 has an essential function in neurogenesis; however, alterations in this gene's regulation occur in melanoma, glioma, and oral and gastric cancers [79-82]. The proto-oncogene ROS1 belongs to the subfamily of tyrosine kinase insulin receptor genes; ROS1 fusions were found in a variety of tumors [83]. The protein product of the SETD3 gene participates in lysine degradation and chromatin organization; alterations in this gene are associated with renal cell carcinoma according to the MalaCards database.

\section{Patient 7}

A 26-year-old female went to a medical facility with a blocked brachial plexus and pain both in the arm and the suprascapular region. The pain felt in the left half of the neck and head, the left arm, and the suprascapular region had bothered her for about a year. Moreover, dizziness and headaches had been present since adolescence. CT and magnetic resonance imaging revealed an unorganized swelling of the neck on the left side, $25 \times$ $20 \mathrm{~mm}$ in size. An US showed that the neoplasm was a hypervascular tumor with its borders on the subclavian artery. A Matas test made to the outpatient was positive: Clamping the CCA caused retrograde blood flow in the supratrochlear artery. During surgery, the tumor was separated from the lateral wall of the CCA and the upper wall of the subclavian artery and excised as a single conglomerate. The tumor, presumably coming from the sympathetic ganglion, was considered as a vagal paraganglioma. Using histological examination, a paraganglioma with an alveolar structure was observed.

In this patient, we found a pathogenic stop-gain mutation NM_003000: c.C79T, p.R27X (chr1: 17371377, rs74315369) in the $S D H B$ gene. This mutation is described in the ClinVar database as a germline variant associated with PGLs/PCCs, hereditary cancerpredisposing syndrome, and early onset renal cell cancer [84-86] (Additional file 1). This mutation results in a premature stop codon in exon 2, disrupting SDHB expression and function.

In this patient's VPGL, we first identified likely pathogenic variants in a number of genes that have previously been found in other tumors according to the COSMIC database: VSIG10 (COSM935687; endometrial cancer), MRGPRX1 (COSM3687222; colon and lung cancer), DUSP27 (COSM144660; diffuse large B cell lymphoma), and C10orf88 (COSM3686556; colon cancer). Moreover, tumor-related alterations were also found for several other genes ( $A B C A 3, A B I 3, A T G 4 C, B L Z F 1, B M P 10$, CHD5, CNKSR1, CRB3, DBH, FAM83A, FAT2, GNA13, KIF26B, MC1R, NR4A1, NUP155, PCM1, SGK2, and $U B R 5)$, in which likely pathogenic variants were observed for VPGLs.

\section{Patient 8}

A 68-year-old female patient had constant episodes of dizziness, headaches, sore throat, and lump feeling in the neck and was examined for a complaint of neoplasms on the left side of the neck. The patient suffered from a long history of arterial hypertension and underwent a surgery for the removal of a thyroid goiter (1990) due to a tumor of the anterior mediastinum (intrathoracic goiter). At surgery, a hypervascular tumor, $60 \mathrm{~mm}$ in diameter, originating from the left vagus nerve, was resected. It was found $30 \mathrm{~mm}$ below the bifurcation of the left CCA and located mainly behind it and behind the ICA and OCA, reaching the base of the skull, involving the ICA in its upper part (the artery was flattened on the upper pole of the tumor). The hyoid and the glossopharyngeal nerves were also removed. Along the sternocleidomastoid muscle, two enlarged lymph nodes were resected and subjected to histological examination. A paraganglioma of alveolar and trabecular histological structure without lymph node metastasis was determined.

Using the whole exome-sequencing, a missense mutation in the SDHD gene, NM_003002: c.A305G, p.H102R (chr11: 111959726, rs104894302), was determined in the VPGL (Additional file 1). This was the same mutation that was identified in Patient 6 (described above).

According to the COSMIC database, we found likely pathogenic variants that were earlier detected in other malignancies: TLL1 (COSM1671424; colorectal cancer), CDH8 (COSM972084; endometrial, pancreatic, and skin cancer), ANAPC5 (COSM936016; endometrial cancer), ACAN (COSM3690591, COSM3690590; colon cancer), C7orf72 (COSM3698459; colon cancer), and ZNF599 (COSM328007; pancreatic cancer).

Additionally, likely pathogenic variants were revealed in well-known tumor-associated genes. For example, variant NM_004996: c.C3901T, p.R1301C (chr16: 16225727, rs201533167) was detected in the $A B C C 1$ gene; this variant seems to be pathogenic according to all the prediction tools used for analysis. $\mathrm{ABCC} 1$ belongs to the superfamily of ATP-binding cassette (ABC) transporters and plays an important role in the response to cancer chemotherapy [87]. The ALDH1L1 gene, in which 
we found the likely pathogenic variant NM_012190: c.G68A, p.G23D (chr3: 125879755 , rs143122118), is a potential tumor suppressor gene, encoding for a protein involved in folate metabolism [88]. A likely pathogenic variant NM_007194: c.T1091C, p.I364T (chr22: 29092893, rs774179198) was revealed in the CHEK2 gene, which is commonly mutated in hereditary cancer [89]. In COL4A1, a variant NM_001845: c.G4442A, p.R1481Q (chr13: 110814597, rs376607450) was observed. COL4A1 encodes for the type IV collagen alpha protein that can contribute to tumor cell migration and invasiveness [90]. In the MADD gene, a novel stop-gain variant NM_003682: c.C2077T, p.Q693X (chr11: 47306036) was found. This gene is involved in tumor cell growth and metastasis [91]. In this patient's VPGL, we also observed a variant NM_ 015641: c.G1123A, p.V375M (chr7: 115897393, rs202205760) in TES, a tumor suppressor gene involved in the regulation of tumorigenesis, angiogenesis, and metastasis [92]. Additionally, a likely pathogenic variant NM 017672: c.C1337G, p.A446G (chr15: 50916466) in the TRPM7 gene was found. This gene encodes for a protein that acts as both an ion channel and a serine/threonineprotein kinase. A few studies considered TRPM7 as a potential biomarker and therapeutic target for many tumors, including pancreatic, breast, gastric, and ovarian cancers, glioblastoma, $\mathrm{T}$ cell leukemia, and hypopharyngeal squamous cell carcinoma [93].

\section{Conclusions}

In this study, exome data of 8 female patients with VPGL were analyzed. In 6 of them, we revealed the existence of pathogenic/likely pathogenic variants of genes encoding for components of the SDH complex (SDHB, SDHD, $S D H A F 3$, and SDHAF4), confirming their high mutation frequency not only in paragangliomas and pheochromocytomas but also in VPGLs as distinct tumor types. Moreover, likely pathogenic variants were identified in different tumor-associated genes as well as variants that have previously been found in common tumors, such as lung, colorectal, endometrial, and renal cancers. Our results indicate a high heterogeneity among VPGLs that is supported by a wide number of identified pathogenic/likely pathogenic variants in different genes (besides mutations in $S D H x /$ SDHAF1-4 genes) in each patient. Obtained data contribute to a better understanding of involvement of specific genes and possible molecular mechanisms in the pathogenesis of this kind of tumor.

\section{Supplementary information}

Supplementary information accompanies this paper at https://doi.org/10 1186/s12920-020-00763-4.

Additional file 1. Pathogenic/likely pathogenic variants identified in the patients with vagal paragangliomas. (XLS $339 \mathrm{~kb}$ )

\section{Abbreviations}

PGL: Paraganglioma; PCC: Pheochromocytoma; HNPGL: Head and neck paraganglioma; VPGL: Vagal paraganglioma; CPGL: Carotid paraganglioma; CT: Computed tomography; DS: Duplex scanning; MRI: Magnetic resonance imaging; CCA: Common carotid artery; ICA: Internal carotid artery;

OCA: Outer carotid artery; SDH: Succinate dehydrogenase

\section{Acknowledgments}

The authors thank the Vishnevsky Institute of Surgery for tissue samples, the National Medical Research Center of Radiology and A. N. Severtsov Institute of Ecology and Evolution for assistance in data analysis. The authors also thank the Center for Precision Genome Editing and Genetic Technologies for Biomedicine, EIMB RAS for providing the computing power and techniques for the data analysis. This work was performed using the equipment of EIMB RAS "Genome" center (http://www.eimb.ru/ru1/ckp/ccu_genome_c.php).

\section{About this supplement}

This article has been published as part of BMC Medical Genomics Volume 13 Supplement 8, 2020: Selected Topics in "Systems Biology and Bioinformatics" - 2019: medical genomics. The full contents of the supplement are available online at https://bmcmedgenomics.biomedcentral.com/articles/supplements/ volume-13-supplement-8.

\section{Authors' contributions}

AVK, DVK, and AVS designed the work; AVK, VSP, MVS, MSF, DVK, and AVS wrote the manuscript; MSF, EAP, AAK, ZGG, and GSR performed experimental procedures; ALG, APP, ENS, and AAP managed the patients and analyzed case history; SAS, NVM, AAD, and GSK analyzed exome-sequencing data; TBD and AVK performed data interpretation. All authors read and approved the final manuscript.

\section{Funding}

This work, including design of the study, collection of paraganglioma samples, high-throughput exome sequencing, data analysis and interpretation, as well as the writing of the manuscript, and publication costs were financially supported by the Russian Science Foundation, grant no. 19-1500419.

\section{Availability of data and materials}

All data generated or analyzed in this study are included in the published article. The sequence data are available in the NCBI SRA under the accession number PRJNA561073.

\section{Ethics approval and consent to participate}

The study was approved by the ethics committee from the Vishnevsky Institute of Surgery and performed according to the Declaration of Helsinki (1964). All patients provided a written informed consent for their participation in the study. Written informed consent was obtained from all of the participants.

\section{Consent for publication}

Written informed consent was obtained from the patients for publication of this study.

\section{Competing interests}

The authors declare that they have no competing interests.

\section{Author details}

'Engelhardt Institute of Molecular Biology, Russian Academy of Sciences, Moscow, Russia. ${ }^{2}$ Vishnevsky Institute of Surgery, Ministry of Health of the Russian Federation, Moscow, Russia. ${ }^{3}$ National Medical Research Radiological Center, Ministry of Health of the Russian Federation, Moscow, Russia. ${ }^{4}$ A. N. Severtsov Institute of Ecology and Evolution, Russian Academy of Sciences, Moscow, Russia.

Received: 23 July 2020 Accepted: 5 August 2020 Published: 18 September 2020

\section{References}

1. Martin TP, Irving RM, Maher ER. The genetics of paragangliomas: a review. Clin Otolaryngol. 2007;32(1):7-11. 
2. Goehler LE, Relton JK, Dripps D, Kiechle R, Tartaglia N, Maier SF, Watkins LR. Vagal paraganglia bind biotinylated interleukin-1 receptor antagonist: a possible mechanism for immune-to-brain communication. Brain Res Bull. 1997:43(3):357-64.

3. Morgan M, Pack RJ, Howe A. Structure of cells and nerve endings in abdominal vagal paraganglia of the rat. Cell Tissue Res. 1976;169(4):467-84

4. Biller HF, Lawson W, Som P, Rosenfeld R. Glomus vagale tumors. Ann Otol Rhinol Laryngol. 1989;98(1 Pt 1):21-6.

5. Offergeld C, Brase C, Yaremchuk S, Mader I, Rischke HC, Glasker S, Schmid KW, Wiech T, Preuss SF, Suarez C, et al. Head and neck paragangliomas: clinical and molecular genetic classification. Clinics. 2012;67(Suppl 1):19-28.

6. El-Naggar AK, Chan JKC, Rubin Grandis J, Takata T, Slootweg PJ. WHO classification of head and neck tumours. Lyon: International Agency for Research on Cancer; 2017.

7. Kotsis T, Christoforou P. Vagal Paraganglioma: surgical removal with superior laryngeal nerve preservation. Vasc Specialist Int. 2019;35(2):105-10.

8. Kataria T, Bisht SS, Mitra S, Abhishek A, Potharaju S, Chakarvarty D. Synchronous malignant vagal paraganglioma with contralateral carotid body paraganglioma treated by radiation therapy. Rare Tumors. 2010;2(2): e21.

9. Hamersley ER, Barrows A, Perez A, Schroeder A, Castle JT. Malignant Vagal Paraganglioma. Head Neck Pathol. 2016;10(2):201-5.

10. Varoquaux A, Kebebew E, Sebag F, Wolf K, Henry JF, Pacak K, Taieb D. Endocrine tumors associated with the vagus nerve. Endocr Relat Cancer. 2016;23(9):R371-9.

11. Boedeker CC. Paragangliomas and paraganglioma syndromes. GMS Curr Top Otorhinolaryngol Head Neck Surg. 2011;10:Doc03.

12. Papaspyrou K, Mewes T, Rossmann H, Fottner C, Schneider-Raetzke B, Bartsch O, Schreckenberger M, Lackner KJ, Amedee RG, Mann WJ. Head and neck paragangliomas: report of 175 patients (1989-2010). Head Neck. 2012 34(5):632-7.

13. Baysal BE, Willett-Brozick JE, Lawrence EC, Drovdlic CM, Savul SA, McLeod DR, Yee HA, Brackmann DE, Slattery WH 3rd, Myers EN, et al. Prevalence of SDHB, SDHC, and SDHD germline mutations in clinic patients with head and neck paragangliomas. J Med Genet. 2002;39(3):178-83.

14. Neumann HP, Erlic Z, Boedeker CC, Rybicki LA, Robledo M, Hermsen M, Schiavi F, Falcioni M, Kwok P, Bauters C, et al. Clinical predictors for germline mutations in head and neck paraganglioma patients: cost reduction strategy in genetic diagnostic process as fall-out. Cancer Res. 2009:69(8):3650-6.

15. Baysal BE. Mitochondrial complex II and genomic imprinting in inheritance of paraganglioma tumors. Biochim Biophys Acta. 2013;1827(5):573-7.

16. Bayley JP, Kunst HP, Cascon A, Sampietro ML, Gaal J, Korpershoek E, HinojarGutierrez A, Timmers HJ, Hoefsloot LH, Hermsen MA, et al. SDHAF2 mutations in familial and sporadic paraganglioma and phaeochromocytoma. Lancet Oncol. 2010;11(4):366-72.

17. Hao HX, Khalimonchuk O, Schraders M, Dephoure N, Bayley JP, Kunst H, Devilee P, Cremers CW, Schiffman JD, Bentz BG, et al. SDH5, a gene required for flavination of succinate dehydrogenase, is mutated in paraganglioma. Science. 2009;325(5944):1139-42.

18. Bourgeron T, Rustin P, Chretien D, Birch-Machin M, Bourgeois M, ViegasPequignot E, Munnich A, Rotig A. Mutation of a nuclear succinate dehydrogenase gene results in mitochondrial respiratory chain deficiency. Nat Genet. 1995;11(2):144-9.

19. Korpershoek E, Favier J, Gaal J, Burnichon N, van Gessel B, Oudijk L, Badoual C, Gadessaud N, Venisse A, Bayley JP, et al. SDHA immunohistochemistry detects germline SDHA gene mutations in apparently sporadic paragangliomas and pheochromocytomas. J Clin Endocrinol Metab. 2011; 96(9):E1472-6.

20. Bausch B, Schiavi F, Ni Y, Welander J, Patocs A, Ngeow J, Wellner U, Malinoc $A$, Taschin E, Barbon G, et al. Clinical characterization of the Pheochromocytoma and Paraganglioma susceptibility genes SDHA TMEM127, MAX, and SDHAF2 for gene-informed prevention. JAMA Oncol. 2017;3(9):1204-12

21. Snezhkina AV, Lukyanova EN, Kalinin DV, Pokrovsky AV, Dmitriev AA, Koroban NV, Pudova EA, Fedorova MS, Volchenko NN, Stepanov OA, et al. Exome analysis of carotid body tumor. BMC Med Genet. 2018;11(Suppl 1):17.

22. Boedeker CC, Hensen EF, Neumann HP, Maier W, van Nederveen FH, Suarez C, Kunst HP, Rodrigo JP, Takes RP, Pellitteri PK, et al. Genetics of hereditary head and neck paragangliomas. Head Neck. 2014;36(6):907-16.
23. Zhikrivetskaya SO, Snezhkina AV, Zaretsky AR, Alekseev BY, Pokrovsky AV Golovyuk AL, Melnikova NV, Stepanov OA, Kalinin DV, Moskalev AA, et al. Molecular markers of paragangliomas/pheochromocytomas. Oncotarget. 2017:8(15):25756-82.

24. Ben Aim L, Pigny P, Castro-Vega L, Buffet A, Amar L, Bertherat J, Drui D, Guilhem I, Baudin E, Lussey-Lepoutre C, et al. Targeted next-generation sequencing detects rare genetic events in pheochromocytoma and paraganglioma. J Med Genet. 2019;56(8):513-20.

25. Kudryavtseva AV, Lukyanova EN, Kalinin DV, Zaretsky AR, Pokrovsky AV, Golovyuk AL, Fedorova MS, Pudova EA, Kharitonov SL, Pavlov VS, et al. Mutational load in carotid body tumor. BMC Med Genet. 2019;12(Suppl 2):39.

26. Bolger AM, Lohse M, Usadel B. Trimmomatic: a flexible trimmer for Illumina sequence data. Bioinformatics. 2014;30(15):2114-20.

27. Li H, Durbin R. Fast and accurate long-read alignment with burrowswheeler transform. Bioinformatics. 2010;26(5):589-95.

28. Li H, Handsaker B, Wysoker A, Fennell T, Ruan J, Homer N, Marth G, Abecasis $\mathrm{G}$, Durbin $\mathrm{R}$, Genome project data processing $\mathrm{S}$. The sequence alignment/ map format and SAMtools. Bioinformatics. 2009;25(16):2078-9.

29. McKenna A, Hanna M, Banks E, Sivachenko A, Cibulskis K, Kernytsky A, Garimella K, Altshuler D, Gabriel S, Daly M, et al. The genome analysis toolkit: a MapReduce framework for analyzing next-generation DNA sequencing data. Genome Res. 2010;20(9):1297-303.

30. Wang $\mathrm{K}$, Li M, Hakonarson $\mathrm{H}$. ANNOVAR: functional annotation of genetic variants from high-throughput sequencing data. Nucleic Acids Res. 2010; 38(16):e164.

31. Zeng ZP, Liu GQ, Li HZ, Fan XR, Liu DM, Tong AL, Zheng X, Liu C. The effects of urotensin-II on proliferation of pheochromocytoma cells and mRNA expression of urotensin-II and its receptor in pheochromocytoma tissues. Ann N Y Acad Sci. 2006;1073:284-9.

32. Liu GQ, Zeng ZP, Li HZ, Fan XR, Liu DM, Tong AL, Zheng X, Liu C. Expression of urotensin II and G-protein coupled receptor 14 mRNA in human pheochromocytoma tissues. Zhongguo Yi Xue Ke Xue Yuan Xue Bao. 2005;27(4):457-60

33. Snezhkina AV, Lukyanova EN, Fedorova MS, Kalinin DV, Melnikova NV, Stepanov OA, Kiseleva MV, Kaprin AD, Pudova EA, Kudryavtseva AV. Novel genes associated with the development of carotid Paragangliomas. Mol Biol. 2019;53(4):613-26.

34. Radestock Y, Hoang-Vu C, Hombach-Klonisch S. Relaxin reduces xenograft tumour growth of human MDA-MB-231 breast cancer cells. Breast Cancer Res. 2008;10(4):R71.

35. Binder C, Chuang E, Habla C, Bleckmann A, Schulz M, Bathgate R, Einspanier A. Relaxins enhance growth of spontaneous murine breast cancers as well as metastatic colonization of the brain. Clin Exp Metastasis. 2014:31(1):57-65.

36. Radestock Y, Willing C, Kehlen A, Hoang-Vu C, Hombach-Klonisch S. Relaxin enhances S100A4 and promotes growth of human thyroid carcinoma cell xenografts. Mol Cancer Res. 2010;8(4):494-506.

37. Feng S, Agoulnik IU, Li Z, Han HD, Lopez-Berestein G, Sood A, Ittmann MM, Agoulnik Al. Relaxin/RXFP1 signaling in prostate cancer progression. Ann N Y Acad Sci. 2009;1160:379-80.

38. Fue M, Miki Y, Takagi K, Hashimoto C, Yaegashi N, Suzuki T, Ito K. Relaxin 2/ RXFP1 Signaling Induces Cell Invasion via the beta-Catenin Pathway in Endometrial Cancer. Int J Mol Sci. 2018;19(8):2438.

39. Glogowska A, Kunanuvat U, Stetefeld J, Patel TR, Thanasupawat T, Krcek J, Weber E, Wong GW, Del Bigio MR, Hoang-Vu C, et al. C1q-tumour necrosis factor-related protein 8 (CTRP8) is a novel interaction partner of relaxin receptor RXFP1 in human brain cancer cells. J Pathol. 2013;231(4):466-79.

40. Thanasupawat T, Glogowska A, Nivedita-Krishnan S, Wilson B, Klonisch T, Hombach-Klonisch S. Emerging roles for the relaxin/RXFP1 system in cancer therapy. Mol Cell Endocrinol. 2019;487:85-93.

41. Croucher DR, Hochgrafe F, Zhang L, Liu L, Lyons RJ, Rickwood D, Tactacan CM, Browne BC, Ali N, Chan $\mathrm{H}$, et al. Involvement of Lyn and the atypical kinase SgK269/PEAK1 in a basal breast cancer signaling pathway. Cancer Res. 2013;73(6):1969-80.

42. Fujimura K, Wright T, Strnadel J, Kaushal S, Metildi C, Lowy AM, Bouvet M, Kelber JA, Klemke RL. A hypusine-elF5A-PEAK1 switch regulates the pathogenesis of pancreatic cancer. Cancer Res. 2014;74(22):6671-81.

43. Guo Q, Qin W, Li B, Yang H, Guan J, Liu Z, Li S. Analysis of a cytoskeletonassociated kinase PEAK1 and E-cadherin in gastric cancer. Pathol Res Pract. 2014;210(12):793-8.

44. Huang L, Wen C, Yang X, Lou Q, Wang X, Che J, Chen J, Yang Z, Wu X, Huang $\mathrm{M}$, et al. PEAK1, acting as a tumor promoter in colorectal cancer, is 
regulated by the EGFR/KRas signaling axis and miR-181d. Cell Death Dis. 2018;9(3):271.

45. Ding C, Tang W, Fan X, Wang X, Wu H, Xu H, Xu W, Gao W, Wu G. Overexpression of PEAK1 contributes to epithelial-mesenchymal transition and tumor metastasis in lung cancer through modulating ERK1/2 and JAK2 signaling. Cell Death Dis. 2018;9(8):802.

46. Marlow R, Binnewies M, Sorensen LK, Monica SD, Strickland P, Forsberg EC, Li DY, Hinck L. Vascular Robo4 restricts proangiogenic VEGF signaling in breast. Proc Natl Acad Sci U S A. 2010;107(23):10520-5.

47. Jiang Z, Liang G, Xiao Y, Qin T, Chen X, Wu E, Ma Q, Wang Z. Targeting the SLIT/ROBO pathway in tumor progression: molecular mechanisms and therapeutic perspectives. Ther Adv Med Oncol. 2019;11:1758835919855238.

48. Dallol A, Krex D, Hesson L, Eng C, Maher ER, Latif F. Frequent epigenetic inactivation of the SLIT2 gene in gliomas. Oncogene. 2003;22(29):4611-6.

49. Lichte B, Veh RW, Meyer HE, Kilimann MW. Amphiphysin, a novel protein associated with synaptic vesicles. EMBO J. 1992;11(7):2521-30.

50. Takei K, Slepnev VI, Haucke V, De Camilli P. Functional partnership between amphiphysin and dynamin in clathrin-mediated endocytosis. Nat Cell Biol. 1999:1(1):33-9.

51. Pittock SJ, Lucchinetti CF, Parisi JE, Benarroch EE, Mokri B, Stephan CL, Kim KK, Kilimann MW, Lennon VA. Amphiphysin autoimmunity: paraneoplastic accompaniments. Ann Neurol. 2005;58(1):96-107.

52. Chen Y, Liu J, Li L, Xia H, Lin Z, Zhong T. AMPH-1 is critical for breast cancer progression. J Cancer. 2018;9(12):2175-82.

53. Dwight T, Na U, Kim E, Zhu Y, Richardson AL, Robinson BG, Tucker KM, Gill AJ, Benn DE, Clifton-Bligh RJ, et al. Analysis of SDHAF3 in familial and sporadic pheochromocytoma and paraganglioma. BMC Cancer. 2017;17(1): 497.

54. Sun WL. Ambra1 in autophagy and apoptosis: implications for cell survival and chemotherapy resistance. Oncol Lett. 2016;12(1):367-74.

55. Yu Y, Walia V, Elble RC. Loss of CLCA4 promotes epithelial-to-mesenchymal transition in breast cancer cells. PLoS One. 2013;8(12):e83943.

56. Chen H, Liu Y, Jiang CJ, Chen YM, Li H, Liu QA. Calcium-activated Chloride Channel A4 (CLCA4) plays inhibitory roles in invasion and migration through suppressing epithelial-Mesenchymal transition via PI3K/AKT signaling in colorectal Cancer. Med Sci Monit. 2019;25:4176-85.

57. Carausu M, Bidard FC, Callens C, Melaabi S, Jeannot E, Pierga JY, Cabel L. ESR1 mutations: a new biomarker in breast cancer. Expert Rev Mol Diagn. 2019;19(7):599-611.

58. Tan Y, Zhang T, Zhou L, Liu S, Liang C. MiR-34b-3p represses the multidrugChemoresistance of bladder Cancer cells by regulating the CCND2 and P2RY1 genes. Med Sci Monit. 2019;25:1323-35.

59. Chiappetta G, Valentino T, Vitiello M, Pasquinelli R, Monaco M, Palma G, Sepe R, Luciano A, Pallante P, Palmieri D, et al. PATZ1 acts as a tumor suppressor in thyroid cancer via targeting p53-dependent genes involved in EMT and cell migration. Oncotarget. 2015;6(7):5310-23.

60. Fedele M, Franco R, Salvatore G, Paronetto MP, Barbagallo F, Pero R, Chiariotti L, Sette C, Tramontano D, Chieffi G, et al. PATZ1 gene has a critical role in the spermatogenesis and testicular tumours. J Pathol. 2008;215(1): 39-47.

61. Bridge JA, Sumegi J, Druta M, Bui MM, Henderson-Jackson E, Linos K, Baker M, Walko CM, Millis S, Brohl AS. Clinical, pathological, and genomic features of EWSR1-PATZ1 fusion sarcoma. Modern Pathol. 2019;32(11):1593-604.

62. Ho MY, Liang CM, Liang SM. PATZ1 induces PP4R2 to form a negative feedback loop on IKK/NF-kappaB signaling in lung cancer. Oncotarget. 2016; 7(32):52255-69.

63. Yang YL, Chu JY, Luo ML, Wu YP, Zhang Y, Feng YB, Shi ZZ, Xu X, Han YL, Cai $Y$, et al. Amplification of PRKCl, located in 3q26, is associated with lymph node metastasis in esophageal squamous cell carcinoma. Genes, Chromosomes Cancer. 2008:47(2):127-36.

64. Campa D, Canzian F, Kaaks R. Genetic variability in the PRKCl gene and prostate cancer risk. Cell Cycle. 2012;11(2):209.

65. Choi EJ, Lee JH, Kim MS, Song SY, Yoo NJ, Lee SH. Intratumoral heterogeneity of somatic mutations for NRIP1, DOK1, ULK1, ULK2, DLGAP3, PARD3 and PRKCI in Colon cancers. Pathol Oncol Res. 2018;24(4):827-32.

66. Guo H, Zhou S, Tan L, Wu X, Wu Z, Ran R. Clinicopathological significance of WIF1 hypermethylation in NSCLC, a meta-analysis and literature review. Oncotarget. 2017;8(2):2550-7.

67. Liu P, Shen JK, Hornicek FJ, Liu F, Duan Z. Wnt inhibitory factor 1 (WIF1) methylation and its association with clinical prognosis in patients with chondrosarcoma. Sci Rep. 2017;7(1):1580.
68. Zhao Z, Liu W, Liu J, Wang J, Luo B. The effect of EBV on WIF1, NLK, and APC gene methylation and expression in gastric carcinoma and nasopharyngeal cancer. J Med Virol. 2017;89(10):1844-51.

69. Hu H, Li B, Zhou C, Ying X, Chen M, Huang T, Chen Y, Ji H, Pan R, Wang T, et al. Diagnostic value of WIF1 methylation for colorectal cancer: a metaanalysis. Oncotarget. 2018;9(4):5378-86.

70. Timmers HJ, Kozupa A, Eisenhofer G, Raygada M, Adams KT, Solis D, Lenders JW, Pacak K. Clinical presentations, biochemical phenotypes, and genotypephenotype correlations in patients with succinate dehydrogenase subunit B-associated pheochromocytomas and paragangliomas. J Clin Endocrinol Metab. 2007;92(3):779-86.

71. Choat H, Derrevere K, Knight L, Brown W, Mack EH. SDHB-associated Paraganglioma in a pediatric patient and literature review on hereditary Pheochromocytoma-Paraganglioma syndromes. Case Rep Endocrinol. 2014; 2014:502734.

72. Ricketts CJ, Shuch B, Vocke CD, Metwalli AR, Bratslavsky G, Middelton L, Yang Y, Wei MH, Pautler SE, Peterson J, et al. Succinate dehydrogenase kidney cancer: an aggressive example of the Warburg effect in cancer. J Urol. 2012;188(6):2063-71.

73. Poeppel TD, Yuece A, Boy C, Metz KA, Kaminsky E, Neumann HP, Rosenbaum SJ, Mann K, Moeller LC. Novel SDHD gene mutation (H102R) in a patient with metastatic cervical paraganglioma effectively treated by peptide receptor radionuclide therapy. J Clin Oncol. 2011;29(33):e812-5.

74. Baysal BE, Ferrell RE, Willett-Brozick JE, Lawrence EC, Myssiorek D, Bosch A, van der Mey A, Taschner PE, Rubinstein WS, Myers EN, et al. Mutations in SDHD, a mitochondrial complex II gene, in hereditary paraganglioma. Science. 2000;287(5454):848-51.

75. Burnichon N, Rohmer V, Amar L, Herman P, Leboulleux S, Darrouzet V, Niccoli P, Gaillard D, Chabrier G, Chabolle F, et al. The succinate dehydrogenase genetic testing in a large prospective series of patients with paragangliomas. J Clin Endocrinol Metab. 2009;94(8):2817-27.

76. Piccini V, Rapizzi E, Bacca A, Di Trapani G, Pulli R, Giache V, Zampetti B, Lucci-Cordisco E, Canu L, Corsini E, et al. Head and neck paragangliomas: genetic spectrum and clinical variability in 79 consecutive patients. Endocr Relat Cancer. 2012;19(2):149-55.

77. Kinoshita T, Nohata N, Watanabe-Takano H, Yoshino H, Hidaka H, Fujimura L, Fuse M, Yamasaki T, Enokida H, Nakagawa M, et al. Actin-related protein 2/3 complex subunit 5 (ARPC5) contributes to cell migration and invasion and is directly regulated by tumor-suppressive microRNA-133a in head and neck squamous cell carcinoma. Int J Oncol. 2012;40(6):1770-8.

78. Xiong T, Luo Z. The expression of actin-related protein $2 / 3$ complex subunit 5 (ARPC5) expression in multiple myeloma and its prognostic significance. Med Sci Monit. 2018;24:6340-8.

79. Bhat KM, Maddodi N, Shashikant C, Setaluri V. Transcriptional regulation of human MAP 2 gene in melanoma: role of neuronal bHLH factors and Notch1 signaling. Nucleic Acids Res. 2006;34(13):3819-32.

80. Yi R, Feng J, Yang S, Huang X, Liao Y, Hu Z, Luo M. miR-484/MAP 2/C-Mycpositive regulatory loop in glioma promotes tumor-initiating properties through ERK1/2 signaling. J Mol Histol. 2018:49(2):209-18.

81. Liu SY, Chen YT, Tseng MY, Hung CC, Chiang WF, Chen HR, Shieh TY, Chen $\mathrm{CH}$, Jou YS, Chen JY. Involvement of microtubule-associated protein 2 (MAP 2) in oral cancer cell motility: a novel biological function of MAP 2 in nonneuronal cells. Biochem Biophys Res Commun. 2008;366(2):520-5.

82. Zheng S, Shi L, Zhang Y, He T. Expression of SNCG, MAP 2, SDF-1 and CXCR4 in gastric adenocarcinoma and their clinical significance. Int J Clin Exp Pathol. 2014;7(10):6606-15.

83. Shaw AT, Hsu PP, Awad MM, Engelman JA. Tyrosine kinase gene rearrangements in epithelial malignancies. Nat Rev Cancer. 2013;13(11):77287.

84. Graham D, Gooch M, Ye Z, Richer E, Chishti A, Reilly E, D'Orazio J. Pheochromocytoma in a twelve-year-old girl with SDHB-related hereditary Paraganglioma-Pheochromocytoma syndrome. Case Rep Genetics. 2014; 2014:273423.

85. Naito M, Usui T, Tamanaha T, Kawashima ST, logawa H, Hagiwara H, Kimura T, Tagami T, Kurosawa M, Shimatsu A, et al. R27X nonsense mutation of the SDHB gene in a patient with sporadic malignant paraganglioma. Endocrine. 2009;36(1):10-5

86. Vanharanta S, Buchta M, McWhinney SR, Virta SK, Peczkowska M, Morrison $C D$, Lehtonen $R$, Januszewicz $A$, Jarvinen $H$, Juhola $M$, et al. Early-onset renal cell carcinoma as a novel extraparaganglial component of SDHB-associated heritable paraganglioma. Am J Hum Genet. 2004;74(1):153-9. 
87. Kunicka T, Soucek P. Importance of ABCC1 for cancer therapy and prognosis. Drug Metab Rev. 2014;46(3):325-42.

88. Krupenko SA, Krupenko NI. Loss of ALDH1L1 folate enzyme confers a selective metabolic advantage for tumor progression. Chem Biol Interact. 2019;302:149-55.

89. Honrado E, Osorio A, Palacios J, Benitez J. Pathology and gene expression of hereditary breast tumors associated with BRCA1, BRCA2 and CHEK2 gene mutations. Oncogene. 2006;25(43):5837-45.

90. Jin R, Shen J, Zhang T, Liu Q, Liao C, Ma H, Li S, Yu Z. The highly expressed COL4A1 genes contributes to the proliferation and migration of the invasive ductal carcinomas. Oncotarget. 2017;8(35):58172-83.

91. Saini S, Sripada L, Tulla K, Kumar P, Yue F, Kunda N, Maker AV, Prabhakar BS. Loss of MADD expression inhibits cellular growth and metastasis in anaplastic thyroid cancer. Cell Death Dis. 2019;10(2):145.

92. Yongbin Y, Jinghua L, Zhanxue Z, Aimin Z, Youchao J, Yanhong S, Manjing J. TES was epigenetically silenced and suppressed the epithelialmesenchymal transition in breast cancer. Tumour Biol. 2014;35(11):11381-9.

93. Yee NS. Role of TRPM7 in Cancer: Potential as Molecular Biomarker and Therapeutic Target. Pharmaceuticals. 2017;10(2):39.

\section{Publisher's Note}

Springer Nature remains neutral with regard to jurisdictional claims in published maps and institutional affiliations.

\section{Ready to submit your research? Choose BMC and benefit from:}

- fast, convenient online submission

- thorough peer review by experienced researchers in your field

- rapid publication on acceptance

- support for research data, including large and complex data types

- gold Open Access which fosters wider collaboration and increased citations

- maximum visibility for your research: over $100 \mathrm{M}$ website views per year

At $\mathrm{BMC}$, research is always in progress.

Learn more biomedcentral.com/submissions 